\title{
Pemanfaatan Pangkasan Biomasa Gamal dan Rumput Gajah sebagai Pupuk Hijau dalam Upaya Peningkatan Pertumbuhan dan Produksi Jagung (Zea mays L.)
}

\author{
Andri Prasetia ${ }^{1}$, Jefri Sembiring ${ }^{1}$, Rangga Kusumah ${ }^{1}$, dan Yopi Tamelan ${ }^{2}$ \\ ${ }^{1}$ Fakultas Pertanian, Universitas Musamus \\ ${ }^{2}$ Program Studi Agroteknologi, Fakultas Pertanian, Universitas Musamus \\ Jl. Kamizaun Mopah Lama, Merauke 99600 \\ *Alamat korespondensi: jsembiring@unmus.ac.id
}

\begin{tabular}{lrc}
\hline \multicolumn{2}{c}{ INFO ARTIKEL } & ABSTRACT/ABSTRAK \\
\hline Diterima: & $06-03-2021$ & \\
Direvisi: & $04-11-2021$ & The Use of Gamal and Elephant Grass Pruned Biomasses to Increase the \\
Dipublikasi: & $23-01-2022$ & Growth and Production of Corn
\end{tabular}

Keywords:

Corn, Elephant grass, Gamal biomass, Growth, Production

Kata Kunci:

Biomasa Gamal, Jagung, Pertumbuhan, Produksi, Rumput Gajah
Corn commodity has been widely developed in Merauke Regency. The geographical condition of Merauke Regency which is a lowland does not have a volcano that can increase or improve soil fertility so that the nutritional needs of plants so far have come from the addition of inorganic fertilizers and monoculture cropping patterns carried out by farmers, thereby reducing land fertility. This study aimed to determine the use of pruning of gamal biomass and elephant grass as an effort to increase the growth and production of corn. The study was carried out in Yasa Mulya Village, Tanah Miring District, Merauke Regency, Papua Province from March to September 2018. The design used was a Randomized Block Design (RBD) with four treatments and four replications. The components of each treatment were P0 (corn monoculture system), P1 (maize and gamal biomass), P2 (maize and elephant grass biomass), P3 (maize, gamal biomass, and elephant grass). Parameters observed included plant height, number of leaves, length of ear, diameter of ear, number of rows of seeds per ear, weight of plant ear and plant production per plot. The data obtained were analyzed for variance (ANOVA) at the level $10 \%$ and continued with the significant difference test (LSD). The results showed that the use of pruning of gamal biomass and elephant grass had an effect on plant height, number of leaves, length of ear, number of rows of seeds per ear, weight of plant cobs and plant production/plot. Treatment of corn, gamal biomass, and elephant grass in an area of $100 \mathrm{~m}^{2}$ reached $4.5 \mathrm{~kg} / \mathrm{plot}$ when converted to hectares, the production reached $4,500 \mathrm{~kg} / \mathrm{ha}(4.50$ tons).

Komoditi jagung telah banyak dikembangkan di Kabupaten Merauke. Kondisi geografis Kabupaten Merauke yang merupakan dataran rendah tidak memiliki gunung berapi yang dapat menambah atau memperbaiki kesuburan tanah sehingga kebutuhan nutrisi tanaman selama ini berasal dari penambahan pupuk anorganik dan pola tanam monokultur yang dilakukan para petani sehingga semakin menurunkan kesuburan lahan. Penelitian ini bertujuan untuk mengetahui pemanfaatan pangkasan biomasa gamal dan rumput gajah sebagai upaya peningkatan pertumbuhan dan produksi jagung. Penelitian dilaksanakan di Desa Yasa Mulya Distrik Tanah Miring Kabupaten Merauke Provinsi Papua pada bulan Maret 
sampai September 2018. Rancangan yang digunakan adalah Rancangan Acak Kelompok (RAK) dengan empat perlakuan dan empat ulangan. Komponen setiap perlakuan yaitu P0 (sistem monokultur jagung), P1 (jagung dan biomasa gamal), P2 (jagung dan biomasa rumput gajah), P3 (jagung, biomasa gamal, dan rumput gajah). Parameter yang diamati meliputi tinggi tanaman, jumlah daun, panjang tongkol, diameter tongkol, jumlah baris biji per tongkol, berat tongkol tanaman dan produksi tanaman per plot. Data yang diperoleh dianalisis varians (ANOVA) pada level 10\% dan dilanjutkan dengan uji beda nyata (BNT). Hasil penelitian menujukkan bahwa pemanfaatan pangkasan biomasa gamal dan rumput gajah memberikan pengaruh pada tinggi tanaman, jumlah daun, panjang tongkol, jumlah baris biji per tongkol, berat tongkol tanaman dan produksi tanaman per plot. Perlakuan jagung, biomasa gamal dan rumput gajah dalam luasan $100 \mathrm{~m}^{2}$ mencapai $4,5 \mathrm{~kg} /$ plot apabila dikonversi ke satuan hektar maka produksinya mencapai $4.500 \mathrm{~kg} / \mathrm{ha}$ (4,50 ton).

\section{PENDAHULUAN}

Merauke merupakan salah satu kabupaten yang ada di Provinsi Papua. Kabupaten Merauke terletak di bagian selatan Provinsi Papua dengan luas kurang lebih 46.791,63 $\mathrm{km}^{2}$ atau $14,67 \%$ dari keseluruhan wilayah Provinsi Papua. Daerah ini memiliki potensi pengembangan pertanian seperti hortikultura dan tanaman pangan. Salah satu komoditi yang dikembangkan di Kabupaten Merauke adalah jagung (Zea mays L.) (BPS, 2016). Menelaah dari kondisi geografis Kabupaten Merauke yang merupakan dataran rendah tidak memiliki gunung berapi yang dapat menambah atau memperbaiki bahan organik pada tanah sehingga kesuburan tanah selama ini berasal dari penambahan pupuk anorganik.

Pola tanam monokultur yang dilakukan para petani yang berakibat semakin menurunkan kesuburan tanah. Agar bisa menjaga kesuburan tanah perlu adanya pendekatan pengelolaan pertanian yang berorientasi pada pertanian organik yang diharapkan mampu menjaga ketersedian bahan organik dalam tanah sehingga tercapai pertanian yang berkelanjutan baik secara ekologi maupun ekonomi. Penggunaan sistem pertanian monokultur pada tanaman semusim di lahan kering terutama jagung varietas unggul memerlukan input luar yang sangat tinggi untuk mendapatkan produktivitas maksimal. Akibatnya biaya produksi meningkat tanpa disadari oleh petani. Sementara itu, kemampuan lahan memberikan daya dukung terhadap produktivitas tanaman pangan semakin menurun.
Pada akhirnya sistem usahatani lahan kering akan berkembang ke arah degradasi sumberdaya alam dan kehilangan potensinya untuk mendukung peningkatan kesejahteraan masyarakat. Melihat kenyataan tersebut, perlu adanya upaya terobosan untuk mendorong perbaikan lingkungan hidup, dengan mengubah sistem pertanian konvensional menjadi sistem pertanian yang ramah lingkungan. Menurut Naipospos (2004), sistem konvensional cenderung mengarah pada penanaman tanaman yang sama (monokultur) yang mengharuskan pemakaian pupuk kimia (anorganik) dan pestisida secara besar-besaran sehingga menimbulkan kerusakan ekosistem dan pengolahan tanah secara intensif menyebabkan degradasi lahan secara luas dan juga mengakibatkan polusi air permukaan maupun air bawah tanah. Agar bisa menjaga kesuburan tanah perlu adanya pendekatan pengelolaan pertanian yang berorientasi pada pertanian organik yang diharapkan mampu menjaga ketersedian bahan organik dalam tanah sehingga tercapai pertanian yang berkelanjutan baik secara ekologi maupun ekonomi.

Pemanfaatan pangkasan dari gamal dan rumput gajah akan digunakan sebagai mulsa/pupuk hijau agar dapat memperbaiki kesuburan tanah, menjaga kelembapan pada tanah dan menekan gulma. Unsur hara dibutuhkan oleh tanaman untuk pertumbuhannya dan perkembangannya. Adanya pemberian pupuk organik hijau ke dalam tanah menyebabkan tanah tersebut memperoleh suplai unsur-unsur hara yang terkandung dalam pupuk organik hijau terutama unsur nitrogen $(\mathrm{N})$, fosfor $(\mathrm{P})$, kalium $(\mathrm{K})$, kalsium (Ca) dan magnesium $(\mathrm{Mg})$ serta unsur-unsur mikro. Semua unsur hara tersebut 
merupakan unsur esensial bagi tanaman yang dapat menunjang pertumbuhan dan produksi tanaman yang lebih baik (Havlin et al., 2005).

\section{BAHAN DAN METODE}

Penelitian dilaksanakan di Desa Yasa Mulya, Distrik Tanah Miring, Kabupaten Merauke, Provinsi Papua pada bulan Maret sampai dengan September 2018. Perlakuan merupakan penanaman jagung dari benih serta penanaman bibit gamal dan bibit rumput gajah. Pemupukan yang diberikan adalah NPK/Urea, TSP dan $\mathrm{KCl}$ serta pemberian pestisida.

Rancangan yang digunakan dalam penelitian ini rancangan acak kelompok (RAK), yang terdiri dari empat perlakuan diulangi sebanyak empat kali sehingga diperoleh 16 satuan percobaan. Perlakuan percobaan tersebut terdiri dari P0: pertanian monokultur; P1: jagung dan biomasa gamal; P2: jagung dan biomasa rumput gajah; P3: jagung, biomasaa gamal, dan rumput gajah. Variabel pengamatan pada penelitian ini meliputi tinggi tanaman, jumlah daun, panjang tongkol, diameter tongkol, jumlah baris biji pertongkol, berat tongkol tanaman, dan produksi tanaman per plot. Analisis dilakukan dengan uji statistik melalui rancangan acak kelompok, dilanjutkan dengan uji beda nyata (BNT) untuk mengetahui perlakuan yang terbaik.

Pangkasan gamal ditanam pada perlakuan P1 dan P3 sebagai tanaman pagar dengan jarak tanam 5 $\mathrm{m}$ x $1 \mathrm{~m}$. Pada perlakuan P1 hanya tanaman gamal kemudian pangkasannya digunakan sebagai pupuk hijau atau mulsa organik untuk tanaman jagung. Pada perlakuan P3 gamal dipadukan dengan tanaman rumput gajah yang pangkasannya juga digunakan sebagai pupuk hijau atau mulsa organik. Rumput gajah ditanam pada perlakuan P2 dan P3 sebagai tanaman pagar dan ditanam di antara pohon gamal. Pada perlakuan P2 hanya ditanam tanaman rumput gajah yang nanti pangkasannya digunakan sebagai pupuk hijau atau mulsa organik untuk tanaman jagung. Sementara itu, pada perlakuan P3 rumput gajah dicampur dengan tanaman gamal yang pangkasannya digunakan sebagai pupuk hijau atau mulsa organik.

\section{HASIL DAN PEMBAHASAN}

\section{Komponen Pertumbuhan Tinggi tanaman}

Tinggi tanaman jagung pada setiap pengamatan mengalami perubahan (Tabel 1). Pada umur 14 hst komponen pertumbuhan tinggi tanaman jagung menunjukkan bahwa perlakuan perlakuan P3 (pupuk hijau gamal dan rumput gajah) menghasilkan rata-rata tinggi tanaman $22,5 \mathrm{~cm}$, memberikan hasil yang berbeda nyata dengan perlakuan P2 (pupuk hijau rumput gajah) yang menghasilkan rata-rata tinggi tanaman yaitu 20,75 $\mathrm{cm}$, perlakuan P1 (pupuk hijau gamal) yang menghasilkan rata-rata tinggi tanaman $20,74 \mathrm{~cm}$, dan perlakuan P0 (tanpa menggunakan pupuk hijau) yang menghasilkan rata-rata tinggi tanaman yaitu $17,86 \mathrm{~cm}$. Sementara itu, perlakuan P2 dan P1 tidak berbeda nyata, tetapi berbeda nyata dengan perlakuan P0. Pada umur 21 hst jumlah rata-rata tinggi tanaman menunjukkan bahwa perlakuan P3 (pupuk hijau gamal dan rumput gajah) menghasilkan rata-rata tinggi tanaman jagung tertinggi sebesar $35,89 \mathrm{~cm}$ yang berbeda nyata dengan perlakuan P1 (pupuk hijau gamal) dan perlakuan P0 (tanpa mengunakan pupuk hijau) tetapi tidak berbeda nyata dengan perlakuan P2 (pupuk hijau rumput gajah).

Tabel 1. Rata-rata tinggi tanaman jagung

\begin{tabular}{lcccccc}
\hline \multirow{2}{*}{ Perlakuan } & \multicolumn{5}{c}{ Tinggi tanaman jagung pada berbagai umur pengamatan $(\mathrm{cm})$} \\
\cline { 2 - 7 } & $14 \mathrm{hst}$ & $21 \mathrm{hst}$ & $28 \mathrm{hst}$ & $35 \mathrm{hst}$ & $42 \mathrm{hst}$ & $49 \mathrm{hst}$ \\
\hline P0 & $17,86 \mathrm{a}$ & $31,68 \mathrm{a}$ & $47,98 \mathrm{a}$ & $64,51 \mathrm{a}$ & $76,72 \mathrm{a}$ & $143,07 \mathrm{a}$ \\
P1 & $20,75 \mathrm{~b}$ & $32,49 \mathrm{a}$ & $49,26 \mathrm{a}$ & $66,62 \mathrm{a}$ & $82,73 \mathrm{~b}$ & $155,23 \mathrm{~b}$ \\
P2 & $20,72 \mathrm{~b}$ & $35,12 \mathrm{bc}$ & $51,19 \mathrm{bc}$ & $72,46 \mathrm{bc}$ & $93,13 \mathrm{bc}$ & $152,36 \mathrm{~b}$ \\
P3 & $22,51 \mathrm{c}$ & $35,89 \mathrm{c}$ & $52,89 \mathrm{c}$ & $73,63 \mathrm{c}$ & $94,16 \mathrm{c}$ & $200,64 \mathrm{c}$ \\
\hline \multicolumn{1}{c}{ Anova } & 61,51 & 94,47 & 178,2 & 533,1 & 954,8 & 576,68 \\
\hline \multicolumn{1}{c}{ BNT } & 1,65 & 3,31 & 4,76 & 8,29 & 4,77 & 103,4
\end{tabular}

Keterangan: Angka-angka yang diikuti oleh huruf yang sama menunjukkan berbeda tidak nyata. P0: sistem monokultur jagung, P1: jagung dan biomasa gamal, P2: jagung dan biomasa rumput gajah, P3: jagung, biomasa gamal, dan rumput gajah.

Tinggi tanaman umur 28 hst menujukkan bahwa perlakuan P3 (pupuk hijau gamal dan rumput gajah) dengan rata-rata tinggi tanaman $52,89 \mathrm{~cm}$, berbeda nyata dengan perlakuan P1 (pupuk hijau 
gamal) dengan rata-rata tinggi tanaman 49,26 cm, dan P0 (tanpa mengunakan pupuk hijau) dengan rata-rata tinggi tanaman $47,97 \mathrm{~cm}$, tetapi tidak berbeda nyata dengan perlakuan P2 (pupuk hijau rumput gajah) yang rata-rata tinggi tanaman 51,19 $\mathrm{cm}$. Sedangkan pada perlakuan P2 berbeda nyata dengan perlakuan P1 dan P0. Perlakuan P1 tidak berbeda nyata dengan perlakuan P0. Tinggi tanaman umur 35 hst menghasilkan jumlah rata-rata tinggi tanaman jagung yaitu $73,63 \mathrm{~cm}$, pada perlakuan P3 (pupuk hijau gamal dan rumput gajah), memberikan hasil yang berbeda nyata dengan perlakuan P1 (pupuk hijau gamal) dengan rata-rata tinggi tanaman $66,63 \mathrm{~cm}$, dan perlakuan P0 (tanpa mengunakan pupuk hijau) dengan rata-rata tinggi tanaman $64,50 \mathrm{~cm}$, tetapi tidak berbeda nyata dengan perlakuan P2 (pupuk hijau rumput gajah) dengan rata-rata tinggi tanaman $72,46 \mathrm{~cm}$. Sementara itu, pada perlakuan P2, berbeda nyata dengan perlakuan P1, dan P0. Perlakuan P1 dan P0 tidak berbeda nyata.

Pada umur 42 hst, perlakuan P3 (pupuk hijau gamal dan rumput gajah) rata-rata tinggi tanaman $94,16 \mathrm{~cm}$, memberikan hasil yang berbeda nyata dengan perlakuan P1 (pupuk hijau gamal) dengan rata-rata tinggi tanaman $82,73 \mathrm{~cm}$, dan perlakuan $\mathrm{P0}$ (tanpa mengunakan pupuk hijau) dengan rata-rata tinggi tanaman $76,72 \mathrm{~cm}$, Sedangkan pada perlakuan P2 (pupuk hijau rumput gajah) menghasilkan ratarata tinggi tanaman $93,13 \mathrm{~cm}$, tidak berbeda nyata dengan P3, tetapi berbeda nyata dengan perlakuan P0. Perlakuan P1 dan P2 tidak berbeda nyata, tetapi berbeda nyata dengan perlakuan P0. Rata-rata tinggi tanaman jagung pada umur 49 hst tertinggi yaitu 200,6 cm, terjadi pada perlakuan P3 (pupuk hijau gamal dan rumput gajah) sedangkan pada perlakuan P0 (tanpa mengunakan pupuk hijau) merupakan jumlah rata-rata tinggi tanaman terendah yaitu $143,07 \mathrm{~cm}$.

Pada komponen pertumbuhan tinggi tanaman jagung menunjukkan bahwa perlakuan P3 (pupuk hijau gamal dan rumput gajah) dengan rata-rata tinggi tanaman 200,64 cm berbeda nyata dengan perlakuan P2 (pupuk hijau rumput gajah) dengan rata-rata tinggi tanaman 152,36 cm, P1 (pupuk hijau gamal) rata-rata tinggi tanaman $155,24 \mathrm{~cm}$, dan $\mathrm{P} 0$ (tanpa mengunakan pupuk hijau) rata-rata tinggi tanaman 143,07 cm. Sementara itu, perlakuan P2 tidak berbeda dengan P1, tetapi berbeda nyata dengan perlakuan P0. Perlakuan berpengaruh nyata pada komponen pertumbuhan tanaman jagung baik tinggi tanaman maupun jumlah daun tanaman.
Pertumbuhan tanaman jagung pada lahan kering dipengaruhi oleh perlakuan pangkasan biomasa gamal dan rumput gajah yang diterapkan sebagai pupuk hijau. Pertumbuhan tinggi tanaman dan jumlah daun tanaman jagung pada P3 yang merupakan pemanfaatan pemangkasan biomasa gamal dan rumput gajah memberikan hasil yang lebih baik dan berpengaruh nyata.

Pertumbuhan tanaman jagung yang lebih baik pada perlakuan P3 disebabkan tanaman jagung mendapatkan manfaat dari kombinasi pangkasan biomasa antara tanaman jagung, gamal, rumput gajah sebagai pupuk hijau atau mulsa organik. Menurut Kastalani dkk. (2016), terpenuhinya kebutuhan unsur hara makro dalam hal ini nitrogen yang diduga menyebabkan adanya pengaruh perlakuan pemupukan terhadap pertambahan tinggi tanaman. Pupuk organik selain mengandung bahan organik juga mengandung sejumlah unsur hara makro termasuk $\mathrm{N}$ yang berfungsi merangsang pertumbuhan vegetatif tanaman diantaranya tinggi tanaman, termasuk panjang dan lebar daun. Hal ini disebabkan karena tanah merupakan medium utama untuk pertumbuhan tanaman secara normal dalam memperoleh nutrien sehingga dengan pemberian bahan organik mempunyai perananan penting dalam memperbaiki kesuburan tanah.

Lebih jauh lagi, pupuk organik yang diberikan pada tanaman mengandung bahan organik yang dapat menyediakan unsur hara $\mathrm{N}$ dan unsur hara lainnya. Hal ini menunjukkan bahwa penambahan pupuk organik mampu memperbaiki jumlah daun sehingga diduga dapat meningkatkan proses fotosintesis kemudian energi yang dibutuhkan tanaman untuk pembentukan daun dapat terpenuhi dengan baik. Bertambahnya unsur $\mathrm{N}$ dalam tanah berasosiasi dengan pembentukan klorofil di daun sehingga hal ini meningkatkan proses fotosintesis yang memacu pertumbuhan jumlah daun tanaman. Menurut Oviyanti dkk. (2016), daun gamal dapat dijadikan pupuk organik karena mempunyai kandungan nitrogen yang tinggi sehingga sangat cocok jika diaplikasikan pada tanaman yang menghasilkan bagian vegetatif sebagai bagian tanaman yang dipanen. Gamal juga mempunyai kandungan nitrogen yang cukup tinggi dengan $\mathrm{C} / \mathrm{N}$ rendah, menyebabkan biomasa tanaman ini mudah mengalami dekomposisi.

Pangkasan pohon legum yang berkualias tinggi (kandungan $\mathrm{N}$ tinggi, kandungan lignin dan polifenol rendah) akan mengalami mineralisasi dengan cepat dan dapat menyediakan unsur hara 
dalam jumlah besar pada awal pertumbuhan tanaman, tetapi mungkin kurang memberikan sumbangan terhadap peningkatan kandungan bahan organik tanah serta perbaikan sifat fisik tanah. Hal ini memberikan keuntungan bagi tanaman jagung yang berakar dangkal dalam penyerapan unsur hara (Nuraini, 2006). Perakaran pada sistem ini mampu memompa unsur hara sehingga bisa dimanfaatkan oleh tanaman jagung. Selain itu juga barisan dari tanaman pagar mampu menahan produktifitas lahan dan erosi sehingga dapat dipertahankan. Berdasarkan hasil pengamatan dapat dilihat bahwa terjadi peningkatan tinggi tanaman pada perlakuan pemberian pupuk organik daun gamal. Hal ini karena pupuk tersebut mengandung unsur hara NPK yang dibutuhkan tanaman untuk proses fisiologi dan metabolisme dalam tanaman yang akan memicu pertumbuhan dan tinggi tanaman. Semakin banyak konsentrasi dari pupuk organik daun gamal maka semakin baik kondisi tanaman tanpa menganggu pertumbuhan dan proses metabolismenya. Kandungan unsur hara terutama nitrogen mampu mendorong dan mempercepat pertumbuhan dan pertambahan tinggi tanaman (Mamentu dkk., 2018).

Tanah memiliki peranan utama sebagai sumber unsur hara yang dibutuhkan oleh tanaman dan organisme yang hidup di dalam tanah. Secara langsung, kandungan unsur hara di dalam tanah menentukan kualitas nutrisi tanaman (sebagai pakan dan pangan) yang tumbuh diatasnya dan secara tidak langsung menentukan kualitas nutrisi hewan ternak dan manusia sebagai pengkonsumsi tanaman analisis sifat dasar tanah, seperti $\mathrm{pH}$ dan kandungan bahan organik tanah, dan sifat kimia tanah khususnya kandungan unsur hara di dalam tanah sangat penting dalam penelitian yang berkaitan dengan tanah dan pertumbuhan tanaman. Hasil analisis tanah dari berbagai perlakuan di lahan kering disajikan pada Tabel 2.

Tabel 2. Hasil analisis tanah setelah percobaan pada berbagai perlakuan sistem pertanian

\begin{tabular}{lccccccccccccc}
\hline $\begin{array}{c}\text { Jenis } \\
\text { sampel }\end{array}$ & $\mathrm{pH}$ & $\mathrm{C}$ & $\mathrm{N}$ & $\mathrm{C} / \mathrm{N}$ & $\mathrm{P}_{2} \mathrm{O}_{5}$ & $\mathrm{~K}$ & $\mathrm{Ca}$ & $\mathrm{Mg}$ & $\mathrm{S}$ & $\mathrm{Fe}$ & $\mathrm{Mn}$ & $\mathrm{Cu}$ \\
\hline \multicolumn{1}{c}{} & \multicolumn{1}{c}{$\%$} & & $\mathrm{ppm}$ & \multicolumn{2}{c}{$(\mathrm{cmol}(+) \mathrm{kg}-1)$} & \multicolumn{4}{c}{$\mathrm{mg} / \mathrm{kg}$} \\
\hline Sebelum \\
perlakuan & 6 & 1,52 & 0,15 & 10 & 9,85 & 0,58 & 3,56 & 1,85 & 45,62 & 45,256 & 2,145 & 0,251 \\
P0 & 5,7 & 1,52 & 0,11 & 14 & 10,63 & 0,48 & 4,32 & 0,85 & 52,36 & 39,62 & 0,856 & 0,125 \\
P1 & 5,9 & 1,69 & 0,12 & 14 & 8,65 & 0,52 & 2,56 & 1,36 & 62,32 & 52,14 & 1,241 & 0,365 \\
P2 & 6,2 & 1,79 & 0,12 & 15 & 12,21 & 0,49 & 6,25 & 2,14 & 52,32 & 48,63 & 0,665 & 0,147 \\
P3 & 5,9 & 1,98 & 0,16 & 12 & 10,14 & 0,52 & 5,14 & 1,85 & 49,63 & 37,58 & 1,241 & 0,265 \\
\hline
\end{tabular}

Keterangan: Analisis tanah dilakukan di laboratorium Ilmu Tanah Universitas Hasanuddin, 2018.

Berdasarkan data pada Tabel 2, terjadi perubahan kandungan hara tanah pada berbagai perlakuan. Kandungan bahan organik (C-organik) tertinggi pada P3 $(1,98)$, sementara ketiga perlakuan lainnya P2 (1,79), P1 (1,69) dan P0 $(1,52)$ selisih perbedaanya tidak terlalu jauh. Kandungan $\mathrm{P}$ tertinggi pada P2 dibandingkan dengan P3, P1 dan P0. Namun secara keseluruhan kandungan hara tanah pada perlakuan P3 mengalami peningkatan dibandingkan dengan kandungan hara pada perlakuan lainnya.

\section{Jumlah daun}

Jumlah daun tanaman pada umur 14 hst menunjukkan bahwa perlakuan P3 (pupuk hijau gamal dan rumput gajah) yang menghasilkan ratarata daun tanaman (5,67 helai), memberikan hasil yang berbeda nyata dengan perlakuan P1 (pupuk hijau gamal) dengan rata-rata tinggi tanaman (5,34 helai), dan P0 (tanpa mengunakan pupuk hijau) dengan rata-rata daun tanaman (4,63 helai), tetapi tidak berbeda nyata dengan perlakuan P2 (pupuk hijau rumput gajah) rata-rata jumlah daun tanaman (5,5 helai). Sementara itu, pada perlakuan P2 dan P1 tidak berbeda nyata, tetapi berbeda nyata dengan perlakuan P0.

Jumlah daun tanaman jagung pada setiap pengamatan mengalami perubahan atau penambahan jumlah daun tanaman namun tidak menunjukkan hasil yang berpengaruh nyata. Jumlah daun tanaman umur 21 hst menunjukkan bahwa perlakuan P3 (pupuk hijau gamal dan rumput gajah) dengan rata-rata jumlah daun tanaman (6,23 helai), memberikan hasil yang berbeda nyata dengan perlakuan P1 (pupuk hijau gamal) dengan rata-rata jumlah daun tanaman (5,85 helai), dan perlakuan P0 (tanpa mengunakan pupuk hijau) dengan rata-rata jumlah daun tanaman (5,41 daun), tetapi tidak 
berbeda nyata dengan perlakuan P2 (pupuk hijau rumput gajah) dengan rata-rata jumlah daun tanaman (5,87 helai). Sementara itu, perlakuan P2 dan P1 tidak berbeda nyata, tetapi berbeda nyata dengan perlakuan P0. Pada umur 28 hst menunjukkan bahwa perlakuan P3 (pupuk hijau gamal dan rumput gajah) dengan rata-rata jumlah daun tanaman (6,74 helai), memberikan hasil yang berbeda nyata dengan perlakuan P2 (pupuk hijau rumput gajah) dengan rata-rata jumlah daun tanaman (6,54 helai), dan perlakuan P0 (tanpa mengunakan pupuk) dengan rata-rata jumlah daun tanaman (6,38 helai), tetapi tidak berbeda nyata dengan perlakuan P1 (pupuk hijau gamal) dengan rata-rata jumlah daun tanaman (6,62 helai).

Tabel 3. Rata-rata jumlah daun tanaman jagung

\begin{tabular}{lcccccc}
\hline \multirow{2}{*}{ Perlakuan } & \multicolumn{5}{c}{ Jumlah daun tanaman jagung pada berbagai umur pengamatan (helai) } \\
\cline { 2 - 7 } & $14 \mathrm{hst}$ & $21 \mathrm{hst}$ & $28 \mathrm{hst}$ & $35 \mathrm{hst}$ & $42 \mathrm{hst}$ & $49 \mathrm{hst}$ \\
\hline P0 & $4,63 \mathrm{a}$ & $5,41 \mathrm{a}$ & $6,38 \mathrm{a}$ & $7,38 \mathrm{a}$ & $8,38 \mathrm{a}$ & $12,29 \mathrm{a}$ \\
P1 & $5,34 \mathrm{~b}$ & $5,85 \mathrm{ab}$ & $6,62 \mathrm{bc}$ & $7,62 \mathrm{bc}$ & $8,47 \mathrm{ab}$ & $12,33 \mathrm{ab}$ \\
P2 & $5,5 \mathrm{bc}$ & $5,87 \mathrm{bc}$ & $6,54 \mathrm{~b}$ & $7,48 \mathrm{ab}$ & $8,63 \mathrm{bc}$ & $12,9 \mathrm{~b}$ \\
P3 & $5,67 \mathrm{c}$ & $6,22 \mathrm{c}$ & $6,74 \mathrm{c}$ & $7,74 \mathrm{c}$ & $8,745 \mathrm{c}$ & $13,26 \mathrm{c}$ \\
\hline Anova & 2,77 & 2,17 & 0,33 & 0,36 & 0,38 & 6,91 \\
\hline BNT & 0,24 & 0,46 & 0,10 & 0,10 & 0,10 & 1,05
\end{tabular}

Keterangan: Angka-angka yang diikuti oleh huruf yang sama menunjukkan berbeda tidak nyata. P0: sistem monokultur jagung, P1: jagung dan biomasa gamal, P2: jagung dan biomasa rumput gajah, P3: jagung, biomasa gamal, dan rumput gajah.

Pada perlakuan P1 dan P2 tidak berbeda nyata, tetapi berbeda nyata dengan perlakuan P0. Jumlah daun tanaman pada umur 35 hst, menghasilkan rata-rata jumlah daun tanaman $(7,74$ helai), pada perlakuan P3 (pupuk hijau gamal dan rumput gajah), memberikan hasil yang berbeda nyata dengan perlakuan P2 (pupuk hijau rumput gajah) dengan rata-rata jumlah daun tanaman $(7,48$ helai), dan perlakuan P0 (tanpa mengunakan pupuk hijau) yang menghasilkan rata-rata jumlah daun tanaman (7,37 helai), tetapi tidak berbeda nyata dengan perlakuan P1 (pupuk hijau gamal) yang menghasilkan rata-rata jumlah daun tanaman (7,62 helai). Sedangkan pada perlakuan P1 dan P2 tidak berbeda nyata, tetapi berbeda nyata dengan perlakuan P0.

Pada umur 42 hst pada rata-rata jumlah daun tanaman jagung menunjukan bahwa perlakuan P3 (pupuk hijau gamal dan rumput gajah) menghasikan rata-rata jumlah daun tanaman (8,76 helai), memberikan hasil yang berbeda nyata perlakuan P1 (pupuk hijau gamal) dengan rata-rata jumlah daun tanaman (8,47 helai), dan perlakuan P0 (tanpa mengunakan pupuk hijau) dengan rata-rata jumlah daun tanaman (8,38 daun), tetapi tidak berbeda nyata dengan perlakuan P2 (pupuk hijau rumput gajah) dengan rata-rata jumlah daun tanaman $(8,63$ helai). Sedangkan pada perlakuan P2 dan P1 tidak berbeda nyata dengan perlakuan P1, tetapi berbeda nyata dengan perlakuan P0. Pertumbuhan jumlah daun tanaman jagung pada umur 49 hst menunjukkan bahwa perlakuan P3 (pupuk hijau/gamal dan rumput gajah) menghasilkan jumlah rata-rata daun tanaman (13,25 helai), memberikan hasil yang berbeda nyata dengan perlakuan P2 (pupuk hijau rumput gajah) dengan rata-rata jumlah daun tanaman (12,9 helai), perlakuan P1 (pupuk hijau gamal) dengan rata-rata jumlah daun tanaman (12,32 helai), dan perlakuan P0 (tanpa mengunakan pupuk hijau) rata-rata jumlah daun tanaman (12,29 helai). Sedangkan pada perlakuan P2 tidak berbeda nyata dengan perlakuan $\mathrm{P} 1$, tetapi berbeda nyata dengan perlakuan P0, sedangkan P1 tidak berbeda nyata dengan perlakuan P0. Perlakuan P3 menujukkan hasil terbaik dalam penelitian ini dengan rata-rata jumlah daun tanaman 13,26 helai/umur 49 hst, atau 8,75 helai/umur 42 hst, atau 7,74 helai/umur 35 hst, atau 6,74 helai/umur 28 hst, atau 6,215 helai/umur 21 hst, dan 5,665 helai/umur 14 hst.

\section{Komponen Produksi}

Hasil sidik ragam menujukkan bahwa pangkasaan biomasa gamal dan rumput gajah terhadap tanaman jagung memberikan pengaruh nyata/signifikan terhadap pengamatan panjang tongkol, jumlah baris biji per tongkol, berat tongkol tanaman, produksi tanaman per plot. Sementara itu, pada pengamatan diameter tongkol tidak memberikan pengaruh nyata. Hasil tersebut dapat dilihat pada Tabel 4 . 
Tabel 4. Rata-rata pada pengamatan panjang tongkol, diameter tongkol, jumlah baris per biji pertongkol, produksi tanaman per plot, berat tongkol

\begin{tabular}{cccccc}
\hline Perlakuan & $\begin{array}{c}\text { Panjang tongkol } \\
(\mathrm{cm})\end{array}$ & $\begin{array}{c}\text { Diameter } \\
\text { tongkol }(\mathrm{mm})\end{array}$ & $\begin{array}{c}\text { Jumlah baris } \\
\text { biji per tongkol }\end{array}$ & $\begin{array}{c}\text { Berat tongkol } \\
\text { tanaman }(\mathrm{g})\end{array}$ & $\begin{array}{c}\text { Produksi tanaman } \\
\text { per plot }(\mathrm{kg})\end{array}$ \\
\hline P0 & $12,455 \mathrm{a}$ & $3,84 \mathrm{a}$ & $13,23 \mathrm{a}$ & $3,87 \mathrm{a}$ & $2,93 \mathrm{a}$ \\
P1 & $15,23 \mathrm{~b}$ & $3,93 \mathrm{a}$ & $13,4 \mathrm{a}$ & $5,28 \mathrm{bc}$ & $4,45 \mathrm{bc}$ \\
P2 & $15,32 \mathrm{~b}$ & $3,96 \mathrm{a}$ & $13,43 \mathrm{a}$ & $5,38 \mathrm{c}$ & $4,33 \mathrm{~b}$ \\
P3 & $15,57 \mathrm{c}$ & $3,94 \mathrm{a}$ & $14,45 \mathrm{~b}$ & $5,5 \mathrm{~d}$ & $4,5 \mathrm{c}$ \\
\hline Anova & $29,69^{* *}$ & 1,09 & $64,76^{* *}$ & $11,40^{* *}$ & $10,02^{*}$ \\
\hline BNT & 0,94 & 0,39 & 2,47 & 1,02 & 0,80 \\
\hline
\end{tabular}

Keterangan: Angka-angka yang diikuti oleh huruf yang sama menunjukkan berbeda tidak nyata. P0: sistem monokultur jagung, P1: jagung dan biomasa gamal, P2: jagung dan biomasa rumput gajah, P3: jagung, biomasa gamal, dan rumput gajah.

\section{Panjang tongkol (cm)}

Hasil sidik ragam menujukkan bahwa perlakuan pemberian pupuk hijau gamal dan rumput gajah memberikan pengaruh sangat nyata terhadap panjang tongkol, jumlah baris biji pertongkol, dan berat tongkol tanaman (Tabel 4). Pada komponen produksi panjang tongkol jagung menujukkan bahwa perlakuan P3 $(15,57 \mathrm{~cm})$ memberikan hasil yang berbeda nyata dengan perlakuan P2 $(15,32 \mathrm{~cm})$, P1 $(15,23 \mathrm{~cm})$, dan P0 $(12,46 \mathrm{~cm})$. Perlakuan P2 tidak berbeda nyata dengan perlakuan $\mathrm{P} 1$, tetapi berbeda nyata dengan perlakuan P0. Begitu pula perlakuan P1 yang berbeda nyata dengan perlakuan P0. Perlakuan P3 menunjukkan hasil terbaik dalam penelitian ini dengan produksi $15,57 \mathrm{~cm} /$ panjang tongkol, atau 14,45/jumlah baris biji per tongkol, maupun 5,5 (g)/berat tongkol tanaman, dan 4,5 $\mathrm{kg} /$ produksi tanaman per plot.

\section{Diameter tongkol (mm)}

Hasil sidik ragam menunjukkan bahwa perlakuan pemberian pupuk hijau tidak memberikan pengaruh yang nyata/non signifikan terhadap diameter tongkol (Tabel 4). Perlakuan P3 (3,94 mm) memberikan hasil yang tidak berbeda nyata dengan perlakuan P2 (3,96 mm), P1 (3,93 mm), dan P0 (3,84 $\mathrm{mm})$. Perlakuan P2 tidak berbeda nyata dengan perlakuan P1 dan P0. Begitu pula dengan perlakuan P1 tidak berbeda nyata dengan perlakuan P0.

\section{Jumlah baris biji per tongkol (baris)}

Hasil sidik ragam menujukkan bahwa perlakuan pemberian pupuk hijau pada tanaman jagung memberi pengaruh nyata terhadap jumlah baris biji per tongkol (Tabel 3). Perlakuan P3 (14,44 baris) memberikan hasil yang berbeda nyata dengan perlakuan P2 (13,43 baris), P1 (13,4 baris), dan P0 (13,23 baris). Sedangkan pada perlakuan P2 tidak berbeda nyata dengan perlakuan P1 dan P0. Begitu pula dengan perlakuan P1 tidak berbeda nyata dengan perlakuan P0. Hasil terbaik ditunjukkan oleh perlakuan P3 dengan jumlah baris biji per tongkol adalah 14,45 baris.

\section{Berat tongkol tanaman (g)}

Hasil sidik ragam menunjukkan bahwa perlakuan pemberian pupuk hijau pada tanaman jagung (Zea mays L) memberikan pengaruh sangat nyata terhadap berat tongkol tanaman (Tabel 4). Perlakuan P3 (5,5 g) memberikan hasil yang berbeda nyata dengan perlakuan P2 (5,37 g), P1 (5,27 g), dan P0 (3,87 g). Perlakuan P2 tidak berbeda nyata dengan perlakuan $\mathrm{P} 1$, tetapi berbeda nyata dengan perlakuan P0. Begitu pula dengan perlakuan P1 berbeda nyata dengan perlakuan P0. Hasil terbaik dalam penelitian ini adalah perlakuan P3 dengan berat tongkol tanaman adalah 5,5 g.

\section{Produksi tanaman per plot $(\mathrm{kg})$}

Hasil sidik ragam menunjukkan bahwa perlakuan pemberian pupuk hijau pada tanaman jagung memberikan pengaruh nyata terhadap produksi tanaman per plot (Tabel 4). Perlakuan P3 (4,5 kg) memberikan hasil yang berbeda nyata dengan perlakuan P2 (4,325 kg), dan P0 (2,925 kg), tetapi tidak berbeda nyata dengan perlakuan P1 $(4,45 \mathrm{~kg})$. Perlakuan P1 tidak berbeda nyata dengan perlakuan P2, tetapi berbeda nyata dengan perlakuan P0. Begitu pula dengan perlakuan P2 berbeda nyata dengan perlakuan P0. Hasil terbaik ditunjukkan oleh perlakuan P3 dengan produksi tanaman per plot adalah $4,5 \mathrm{~kg}$.

Berdasarkan hasil penelitian bahwa perlakuan berpengaruh nyata pada produksi tanaman jagung baik produksi panjang tongkol, maupun pada jumlah baris biji per tongkol, atau berat tongkol tanaman, dan produksi tanaman per plot. Hasil penelitian yang telah dilakukan juga menunjukkan bahwa 
besarnya produksi jagung pada lahan kering dipengaruhi oleh perlakuan pemanfaatan pangkasan biomasa gamal dan rumput gajah. Produksi jagung pada P3 yang merupakan pemanfaatan biomasa gamal dan rumput gajah memberikan hasil lebih baik dan berpengaruh nyata. Total rata-rata produksi pada perlakuan P3 dalam luasan $100 \mathrm{~m}^{2}$ mencapai 4,5 kg/plot bila dikonvensi ke satuan hektar maka produksinya mencapai $4.500 \mathrm{~kg} / \mathrm{ha}$ (4,50 ton). Produksi ini lebih tinggi dibandingkan dengan produksi jagung petani Merauke dalam 5 tahun terakhir yang hanya mencapai 3,53 ton/ha.

Produksi jagung yang lebih baik pada P3 disebabkan tanaman jagung mendapatkan manfaat dari pangkasan biomasa antara tanaman jagung, gamal, dan rumput gajah melalui pemanfaatan pangkasan gamal dan rumput gajah yang diberikan sebagai pupuk hijau pada tanaman jagung. Perbedaan penggunaan bahan mulsa akan memberikan pengaruh yang berbeda pada pertumbuhan dan hasil (Koryati, 2004). Komponen tanaman gamal dan rumput gajah pada perlakuan P1, P2, dan P3 digunakan sebagai pupuk hijau untuk tanaman jagung sehingga bisa menabah laju evaporasi (penguapan) dan meningkatkan kandungan unsur hara. Keragaman perakaran pada sistem ini, juga mampu menjaring dan memompa unsur hara sehingga bisa di manfaatkan oleh tanaman jagung. Selain itu barisan (tanaman pagar) gamal dan rumput gajah juga mampu menahan erosi sehingga produktifitas lahan atau tanah dapat dipertahankan dan ditingkatkan. Tjahyo (2003) dalam Suwignyo dkk. (2012) menyatakan bahwa mulsa organik lebih disukai terutama pada sistem pertanian organik. Pemberian mulsa organik memberikan suatu lingkungan pertumbuhan yang baik bagi tanaman karena dapat mengurangi evaporasi, mencegah penyinaran langsung sinar matahari yang berlebihan terhadap tanah serta kelembaban tanah dapat terjaga sehingga tanaman dapat menyerap air dan unsur hara dengan baik.

Tanaman pagar (gamal dan rumput gajah) berfungsi sebagai sumber pupuk hijau atau mulsa organik bagi tanaman semusim. Jika yang digunakan adalah tanaman legum dan pangkasannya dijadikan mulsa organik atau pupuk hijau merupakan sumber nitrogen yang cukup besar bagi tanaman semusim dan dapat memperbaiki sifat fisik tanah. Budidaya jagung monokultur pada lahan kering dengan intensitas curah hujan rendah, sangat rentan terjadi penguapan sehingga dapat menghambat penyerapan unsur hara oleh akar tanaman sehingga perlu dilakukan penutupan tanah dengan mulsa organik atau pupuk hijau. Menurut Chaerunnisa dkk. (2016), penggunaan mulsa organik berfungsi sebagai penambah unsur hara dan dapat menjaga kelembaban pada tanah karena mulsa organik terdiri dari bahan organik sisa tanaman (seresah padi, serbuk gergaji, batang jagung), pangkasan dari tanaman pagar, daun-daun dan ranting tanaman yang akan dapat memperbaiki kesuburan, struktur dan secara tidak langsung akan mempertahankan porositas tanah, yang berarti akan mempertahankan kapasitas tanah menahan air, setelah terdekomposisi. Menurut Forth (1994) dalam Chaerunnisa dkk. (2016), penutupan tanah dengan bahan organik yang berwarna muda dapat memantulkan sebagian besar dari radiasi matahari, menghambat kehilangan panas karena radiasi, meningkatkan penyerapan air dan mengurangi penguapan air di permukaan tanah. Mulsa organik pada permukaan tanah berfungsi mempertahankan kelembaban tanah, menurunkan penguapan tanah dan dapat meningkatkan infitrasi air ke dalam tanah sehinga memengaruhi produksi tanaman jagung. Damaiyanti dkk. (2013) menjelaskan pengaplikasian semua mulsa organik dapat menurunkan kerapatan gulma.

\section{Biomasa Pangkasan Gamal dan Rumput Gajah}

Data potensi pangkasan gamal yang terhitung selama penelitian pada perlakuan P1 dan P3 dengan pemangkasan yang dilakukan setiap satu bulan sekali disajikan pada Tabel 5.

Tabel 5. Produksi pangkasan gamal dan rumput gajah setiap perlakuan

\begin{tabular}{c|c|c|c|c}
\hline \multirow{2}{*}{$\begin{array}{c}\text { Pangkasan } \\
\text { ke- }\end{array}$} & \multicolumn{3}{|c}{ Produksi pangkasan (kg) } \\
\cline { 2 - 5 } & P1 & P3 & P2 & P3 \\
\cline { 2 - 5 } & 32,7 & 20 & 766,5 & 713 \\
\hline 1 & 55,3 & 28 & 561 & 473 \\
\hline 2 & 69,4 & 35,4 & 376 & 304 \\
\hline 3 & 84,5 & 49,9 & 282 & 237 \\
\hline 4 & 241,9 & 133,3 & 1985,5 & 1727 \\
\hline Total & 60,475 & 33,325 & 496,375 & 431,75 \\
\hline Rata-rata & \multicolumn{2}{|c|}{ Gamal } & Rumput gajah \\
\hline Keterangan: P1: jagung dan biomasa gamal, P2: jagung dan \\
biomasa rumput gajah, P3: jagung, biomasa gamal, \\
dan rumput gajah.
\end{tabular}

Produksi bobot total pangkasan yang terbaik ditunjukkan oleh perlakuan P1 yaitu $241,9 \mathrm{~kg}$, sementara pada perlakuan P3 sebesar 133,3 kg/petak. Sementara itu, data potensi pangkasan rumput gajah yang terhitung selama penelitian pada perlakuan P2 
dan P3 menunjukkan potensi bobot total pangkasan yang baik pada perlakuan P2 sebesar 1985,5 kg dan menyusul pada perlakuan P3 sebesar $1727 \mathrm{~kg}$ (Tabel 5).

\section{SIMPULAN}

Pemanfaatan pangkasan biomasa gamal dan rumput gajah terhadap tanaman jagung dapat meningkatkan produksi tanaman jagung mencapai 4,5 toh/ha. Pemanfaatan pangkasan biomasa gamal dan rumput gajah juga memberi pengaruh pada tinggi tanaman $(15,57 \mathrm{~cm})$, jumlah daun $(13,26$ helai), panjang tongkol $(15,57 \mathrm{~cm})$, jumlah baris biji per tongkol (14,45 baris), berat tongkol tanaman $(5,5 \mathrm{~g})$, dan produksi tanaman per plot $(4,5 \mathrm{~kg} / \mathrm{plot})$.

\section{DAFTAR PUSTAKA}

BPS. 2016. Badan Pusat Statistik. Budidaya Tanaman Jagung.

Chaerunnisa, D Hariyono, dan A Suryanto. 2016. Aplikasi penggunaan mulsa dan jumlah biji per lubang tanam terhadap tanaman jagung manis (Zea mays saccharata Sturt.). Jurnal Produksi Tanaman. 4(4): 311-319.

Damaiyanti, R Aini, dan Koesriharti. 2013. Kajian pengunaan mulsa organik pada pertumbuhan dan hasil tanaman cabai besar (Capsicum annuum L.). J. Produksi Tanaman 2(1): 25-32.

Havlin, JL, JD Beaton, SL Tisdale, and WL Nelson, 2005. Soil Fertility and Fertilizers an
Introduction to Nutrient Management. Pearson Education, Inc. New Jersey.

Kastalani, ME Kusuma, dan Boboina. 2016. Respon pertumbuhan vegetatif rumput gajah (Pennisetum purpureum) terhadap aplikasi level pupuk organik dan anorganik. Al Ulum Sains dan Teknologi. 1(2): 79-83.

Koryati, T. 2004. Pengaruh penggunaan mulsa dan pemupukan urea terhadap pertumbuhan dan produksi cabai merah (Capsicum annum L.). Jurnal Penelitian Bidang pertanian. 2(1): 1316.

Mamentu, M, JM Paulus, dan E Lengkong. 2018. Pemberian POC gamal terhadap pertumbuhan dan produksi padi sawah (Oryza sativa L.) dengan metode salibu. Eugenia. 24(1): 27-33.

Naipospos, B. 2004. Pertanian campuran harga mati bagi lingkungan. Sinar Tani. Edisi 28 No. 3032. Jakarta.

Nuraini, 2006. Serapan nitrogen dari pangkasan pohon legume Oleh tanaman pangan pada sistem budidaya pagar. Buana Sains. 6(2): 127136.

Oviyanti, F, S Syarifah, dan N Hidayah. 2016. Pengaruh pemberian pupuk organik cair daun gamal (Gliricidia sepium (Jacq.) Kunth Ex Walp.) terhadap pertumbuhan tanaman sawi (Brassica juncea L.). Jurnal Biota. 2(1): 61-67.

Suwignyo, B, B Suhartanto, dan N Supartini. 2012. Pengaruh tipe mulsa terhadap germinasi dan pertumbuhan tanaman jagung umur masak susu di lahan pasir. Buana Sains. 12(1): 25-30. 